\title{
MARIE GUY-STÉPHAN Y EL JALEO DE JEREZ. UN DAGUERROTIPO DE BAILE ESPAÑOL
}

\author{
Rocío Plaza Orellana ${ }^{1}$ \\ Universidad de Sevilla
}

\begin{abstract}
En este artículo se estudia el daguerrotipo del Instituto del Patrimonio Cultural de España (IPCE), que con el número de referencia SB-9999, representa a la bailarina francesa Marie Guy-Stephan, retratada con la indumentaria del baile del Jaleo de Jerez.

Palabras clave: Daguerrotipo; Ballet; Flamenco; Guy-Stéphan; José de Salamanca; Jaleo de Jerez; Indumentaria; Traje; Baile español.
\end{abstract}

\section{MARIE GUY-STÉPHAN AND EL JALEO DE JEREZ. A DAGUERREOTYPE OF SPANISH DANCE}

This article concerns the daguerreotype in the collection of the Institute of Spanish Cultural Heritage (IPCE) bearing the reference number SB-9999. The daguerreotype represents the French dancer Marie Guy-Stéphan dressed in the costume of the Jaleo de Jerez.

Key words: Daguerreotype; Ballet; Flamenco; Guy-Stéphan; José de Salamanca; Jaleo de Jerez; Clothing; Dress; Spanish Dance.

Cómo citar este artículo / Citation: Plaza Orellana, Rocío (2018): "Marie Guy-Stéphan y el Jaleo de Jeréz un daguerrotipo de baile español”. En: Archivo Español de Arte, vol. 91, núm. 364, Madrid, pp. 418-426. https://doi. $\operatorname{org} / 10.3989 /$ aearte.2018.26.

\section{El daguerrotipo del IPCE y Marie Guy-Stéphan}

El Instituto del Patrimonio Cultural de España (IPCE) posee un daguerrotipo coloreado de una bailarina ataviada con peina, flor y unas castañuelas anudadas a los dedos que sonríe al espectador. Se trata de una de las imágenes más importantes de la historia de la danza española, ya que es el retrato fotográfico más antiguo hasta el momento de una intérprete de bailes españoles. Es un daguerrotipo de placa entera de casi 21 x 15 centímetros, enmarcado en madera recubierto de terciopelo ${ }^{2}$. La pieza fue adquirida en subasta en el año 2010. Publiqué su posible identificación dentro de una monografía titulada Los bailes españoles en Europa. El espectáculo de los bailes de España en el siglo XIX en el año $2013^{3}$, que se citaría en el artículo titulado Marie Guy-Stéphan ${ }^{4}$, indexado dentro del proyecto francés Danse de Wikipédia ${ }^{5}$, concretamente por

\footnotetext{
1 rplaza@us.es / ORCID iD: http://orcid.org/0000-0002-2206-393X.

2 Instituto de la Cultura y del Patrimonio de España, Madrid (IPCE) SB-9999.

3 Plaza, 2013: 263.

${ }^{4} \mathrm{https} / / /$ es.wikipedia.org/wiki/Marie_Guy-St\%C3\%A9phan. Consultado el 18 de enero de 2018.

${ }^{5}$ https://fr.wikipedia.org/wiki/Projet:Danse. Consultado el 18 de enero de 2018.
} 
Fig. 1. Marie Guy-Stéphan. Daguerrotipo.

Instituto del

Patrimonio Cultural de España. Ministerio

de Educación,

Cultura y Deporte.

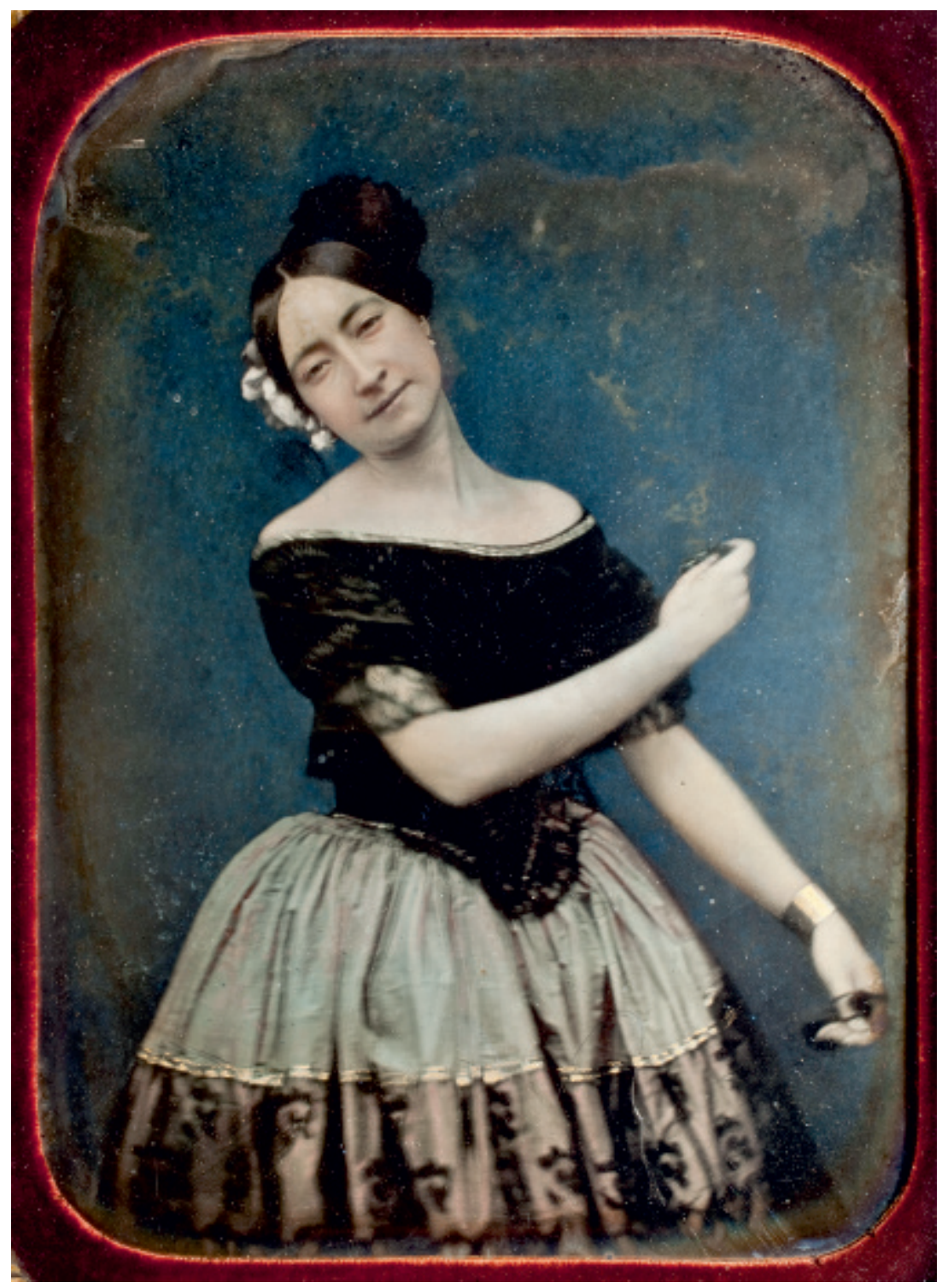

Carlos Teixidor el 6 de enero de 2016 . Si bien apuntaba en esta publicación a Marie, lo cierto es que lo haría basándome en las similitudes físicas de algunas litografías. Desde que tuve conocimiento de la imagen, en 2010, he estado investigando constantemente para buscar los datos que permitieran su definitiva identificación, que son el resultado que expongo en esta publicación. Por tanto, el objetivo de este estudio es ofrecer la identificación definitiva de la bailarina del daguerrotipo, aportando para ello nuevas fuentes concluyentes, así como una fecha lo más concreta posible de su realización (fig. 1).

En lo concerniente a su parecido físico con otras imágenes, la que refleja una fisonomía más parecida en relación con el daguerrotipo, la reproducimos en este trabajo tras haberla hallado recientemente, Se trata de un retrato litográfico publicado en un folleto de cuatro páginas que se

${ }^{6}$ https://fr.wikipedia.org/w/index.php?diff=122047966. Consultado el 18 de enero de 2018. 


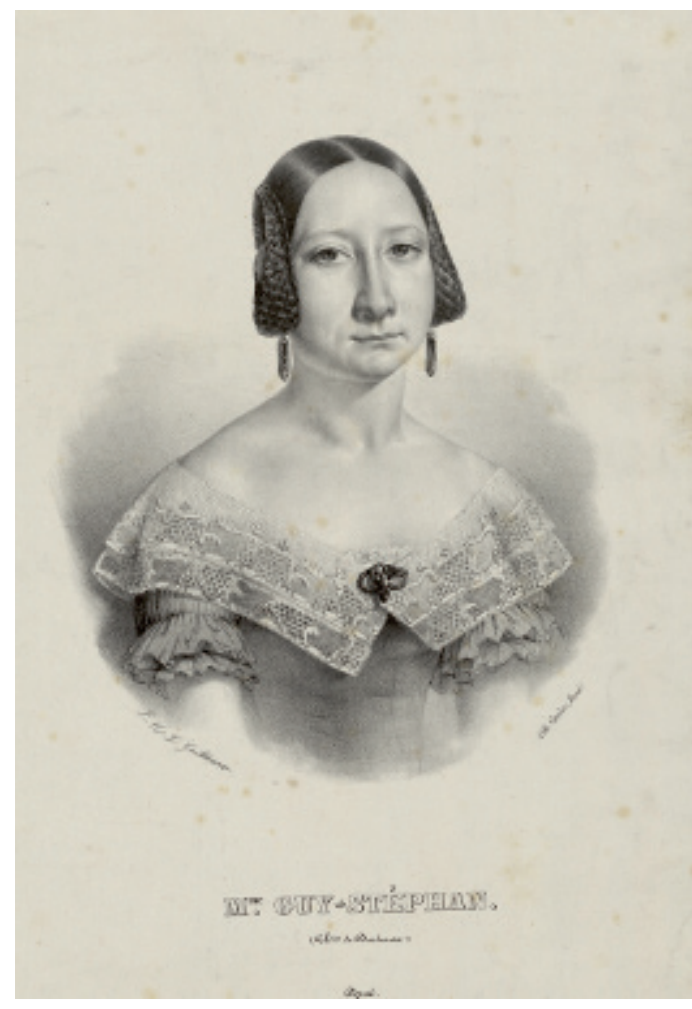

Fig. 2. Marie Guy-Stéphan. Litografía de Gaulon. L.M.D. Guillaume. Bordeaux. Biblioteca Municipal de Burdeos.

publicó en Burdeos en 1843 que acompaña a su biografía. Está realizada por Cyprier Gaulon a partir de un retrato de Louis Mathieu Didier Guillaume ${ }^{7}$ (fig. 2).

En el presente estudio se analizan otros aspectos que nos han permitido trazar un perfil más exacto de la bailarina del daguerrotipo. Por una parte se ha analizado el texto de la "Asamblea General de los caballeros y damas de Triana y toma de hábito en la orden de cierta rubia bailadora" publicada por primera vez en noviembre de 1845 en el Siglo pintoresco ${ }^{8}$, que posteriormente constituiría una de las Escenas Andaluzas que publicaría el mismo autor, Serafín Estébanez Calderón en $1847^{9}$. Si bien es cierto que Luis Lavaur ya apunta a que la protagonista del texto se pueda tratar de Marie Guy-Stéphan, atendiendo a la rotulación que se realiza en un grabado que se insertó en la edición de 1847; en este trabajo se añaden otros datos que nos permiten confirmar su relación con el daguerrotipo.

\section{Marie en las Escenas Andaluzas de Estébanez Calderón}

Marie Antoinette Stephan nació en 1818 , fue miembro del cuerpo de ballet infantil de la Academia Real de Música parisina ${ }^{10}$, actuando en ella con el nombre de Virginie Stephan. Problemas profesionales, así como su cambio de estado, a partir de 1838, la llevaría a deshacerse profesionalmente del nombre con el que había comenzado a bailar, Virginie Stephan, para imponerse definitivamente Marie ${ }^{11}$. Fue Marie la que triunfó en España entre 1843 y 1851. Un nombre que vendría acompañado del apellido de su marido a partir de 1838, cuando ya se haría llamar para siempre Madame Guy-Stéphan, o Marie Guy-Stéphan ${ }^{12}$.

La desaparición de Virginie como nombre artístico, ya en España, resulta imprescindible para comprender la identificación del daguerrotipo del IPCE. La imagen más valiosa que poseemos hasta el momento para establecer la correlación entre este daguerrotipo y la identidad de la bailarina, se la debemos a la publicación de Serafín Estébanez Calderón del texto en noviembre de 1845 en El Siglo pintoresco ${ }^{13}$. En él, la "cierta rubia bailadora" protagonista, tiene por nombre

\footnotetext{
7 MME. Guy Stephane:3. BMB (Biblioteca Municipal de Burdeos). Del. Carton 81/40 (1).

${ }^{8}$ Siglo Pintoresco, Madrid, XI, 1845: 226.

9 Estébanez, Madrid, 1847.

10 Con seis años comenzó a tomar clases con M. Mérante, ingresando en el cuerpo infantil de baile de la Ópera en 1828. Debutaría por primera vez en el ballet de Psyché y el Amor, ofrecido con motivo de la retraite de M. Gardel. MME. Guy Stephane:1, BMB. Del Carton 81/40 (2).

11 Louis Gentil en un manuscrito conservado en Archivo de la Opera de París la recuerda como Virginie, publicado por Tamvaco: 2000. Hasta 1838 en las carteleras aparece como Mlle. V. Stephan. De igual modo utilizaba este nombre también oficialmente. Postes/ actas notariales 16-1844-2MI2133. Cit. Hormigón, 2010: 171.

12 Hormigón, 2010: 171.

13 Siglo Pintoresco, Madrid, XI, 1845: 226.
} 
Virginia. Si bien la "Asamblea General" no revela en ningún momento la identidad de Guy-Stéphan a la que está dedicada la pieza, sin embargo, desde su primera publicación en el Siglo Pintoresco se acompañó de un grabado de F. Lameyer en el que se retrataba a una bailarina con el siguiente epígrafe: "La Guy Stephan en el Jaleo de Jerez"14 (fig. 3).

De igual modo, el anuncio de la publicación de la misma obra que se publicitó como un folleto independiente en 1846 en Madrid en el establecimiento de Castelló y González del Campo, se ilustra con un grabado de Vicente Castelló en el que aparece Marie de nuevo con este traje en el paso del Jaleo de Jerez. En este folleto destaca precisamente su presentación publicitaria, en la que se hace constar: "Asamblea General de los caballeros y damas de Triana dedicada a Mme. Guy Stephan por el Solitario y Castelló"15.

En la publicación de las Escenas Andaluzas que realizó Estébanez Calderón en $1847^{16}$, aparecen entre las ilustraciones de esta escena de la "Asamblea General", un grabado inserto en el texto y un grabado independiente ${ }^{17}$. En ambas imágenes encontramos a la misma bai-

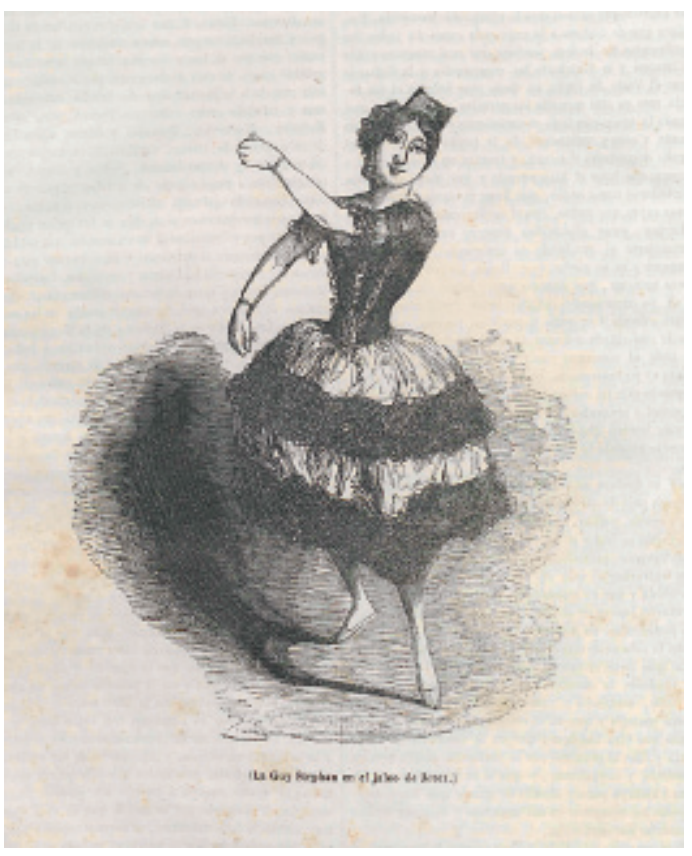

Fig. 3. Francisco Lamayer y Berenguer. Grabado. "La Guy Stephan en el jaleo de Jerez". El

Siglo Pintoresco. Noviembre de 1845. Biblioteca de la Universidad de Sevilla. en la lámina se identifica como "Madame Guy Stephan en el Jaleo". La bailarina "Virginia" de El Solitario, es la bailarina Marie Guy-Stéphan de Serafín Estébanez Calderón. Su vinculación a través de la imagen diseñada por Francisco Lameyer, y grabadas por Vicente Castelló, fundador del Siglo Pintoresco, junto con el editor Baltasar González desde su primera edición, resulta inseparable del texto. Las palabras no ofrecen más que un camuflaje aparente, que potencia una labor propagandística. La "Asamblea general" comparte con el resto de las Escenas del autor, su ausencia de cotidianidad, su ubicación dentro de escenarios festivos, la presencia de personajes que se identificarán como literariamente típicos andaluces, que analiza A. González Troyano en el conjunto de la obra ${ }^{18}$, pero también a una protagonista, ausente, que es totalmente ajena al entorno en el que el autor pretende introducirla. Y que por tanto, participa de las teorías de Borja Rodríguez Gutiérrez, que indican que nos encontramos ante una ausencia de escena costumbrista, tipos costumbristas, físiologías costumbristas: "ni nada que tenga que ver con el costumbrismo"19.

Se trata de la historia de una bailarina profesional extranjera dentro de una escena cuajada de personajes que el autor dispone al servicio de ésta. Sin las imágenes, la identificación de la bailarina en el país resultaría complicada en su momento, pero como la intención no era la de convertirla en una escena-tipo en la línea del costumbrismo, sino en una publicación con un cierto

14 Siglo Pintoresco, Madrid, XI, 1845: 234.

15 Semanario pintoresco español, Madrid, 28-VIII-1846: 272.

16 Estébanez, 1847.

17 En el anuncio que se hizo para su venta, se indicó que se realizaría por entregas como folletos independientes acompañándose cada una de las Escenas con grabados insertos en el texto. El Clamor público, Madrid, 14-X-1846: 4

18 González:1985: 39.

19 Rodríguez, 2011: 741-754. 
carácter publicitario, la relación entre las imágenes y el contenido del texto resulta inseparable, pues fueron concebidas como partes imprescindibles del conjunto.

Estébanez Calderón, "El Solitario", era un habitual del palco que tenía su cuñado José de Salamanca en el Circo durante los años que éste se hizo con la empresa, entre 1843 y 1847. Salamanca invertiría una fortuna en aquel local, no sólo en decorados, diseños, iluminación, mantenimiento, reformas y contratas, sino en agasajar a los invitados con refrescos, regalos y banquetes. Este período resultaría fundamental para su proyección política, pues daría frutos precisamente en el momento en el que se despidió de la empresa del Teatro.

Marie en estos años fue una eficaz embajadora de sus intereses. Cuando la reina Isabel II comenzó a acudir a la sala contaba trece años, y se convirtió en una fiel admiradora de la bailarina, a la que felicitaba públicamente en su palco, le hacía regalos que la prensa aireaba e invitaba a palacio ${ }^{20}$. Estos años de costosas inversiones coincidieron con el retorno de la ex regente María Cristina de su exilio en Roma junto con su esposo el duque de Riansares. Desde su llegada en marzo de 1844, la ex regente se sumó al teatro, como de igual modo, José de Salamanca se convirtió en un asiduo visitante del matrimonio en su palacio de las Rejas, con el que compartiría negocios y deudas. Una relación económica y política basada en especulaciones bursátiles o subastas de ferrocarriles, donde los intereses privados de Salamanca y de los Riansares se encontraron, configurándose negocios particulares en torno a las necesidades y bienes del Esta$\mathrm{do}^{21}$. Actividades que alcanzarían el triunfo político durante la noche del 27 de marzo de 1847, cuando Isabel II acabó con un ministerio que tenía la mayoría en las Cortes, utilizando por primera vez la prerrogativa regia, situándose fuera de las reglas parlamentarias, para entregar el poder a Joaquín Francisco Pacheco, y el ministerio de Hacienda a José de Salamanca ${ }^{22}$. El Faro, en su edición del 27 de junio de 1847, calificaría a aquel nuevo ministerio como "el ministerio del Circo, el ministerio de la Guy Stephan"23. En 1847 desembocaron importantes acontecimientos en esta historia. El esplendor del Circo se apagó con la despedida de José de Salamanca. Se retiraba para legislar desde el Ministerio de Hacienda. Por su parte, su cuñado Estébanez Calderón, a la vez que veía publicadas completas sus Escenas Andaluzas, se vio obligado a retornar a la política, "presionado por Salamanca"24, aceptando ser ministro togado del Tribunal Supremo. Mientras Marie, aprobada por aquel tribunal popular que la juzgó en un corral de Triana sacado de la fantasía de su "Solitario", abandonó también el Circo para firmar importantes contratas por todo el país como la bailarina más importante de su tiempo.

\section{El traje del Jaleo de Jerez}

Marie Guy-Stéphan había sido contratada por el teatro del Circo de Madrid en 1843 para que diera vida a un repertorio de ballet clásico, con la intención de multiplicar los ingresos de taquilla ante la necesidad de ofrecer espectáculos distinguidos, complejos y costosos para el acomodado público que lo frecuentaba, mientras se concluían las obras del Teatro Real. El 28 de enero de 1845 lograría un triunfo inesperado, pero rotundo y sólido, interpretando un Jaleo de Jerez compuesto para ella por Victorino Vera dentro del ballet El diablo enamorado.

En el daguerrotipo aparece ataviada con el traje con el que bailó el Jaleo de Jerez en el Teatro del Circo con las mismas prendas y los mismos complementos con los que la retrató Francisco Lameyer y Berenguer para las ilustraciones al texto de "El solitario" que publicó en el Siglo Pintoresco tan sólo diez meses después, concretamente en noviembre de $1845^{25}$ y a las de las

\footnotetext{
20 El Heraldo, Madrid, 22-I-1844: 3; El Heraldo, Madrid, 27-I-1844: 3; El Laberinto, Madrid, 1-II-1844: 96.

21 Burdiel, 2010: 266, Llorca, 1984: 142; Borrego, 1855: 142-143.

22 Burdiel, 2010: 196.

23 El Faro, Madrid, 27-VI-1847. Cit. por Lavaur, 1999: 149-150.

24 http:www.rah.es/serafin-estebanez-calderon. Consultado el 4 de septiembre de 2017.

25 Siglo Pintoresco, Madrid, XI, 1845: 226.
} 
Escenas Andaluzas de $1847^{26}$. Por esto, la imagen de Marie en el daguerrotipo podría posiblemente encuadrarse dentro de este marco temporal, entre marzo de 1845 y 1847 (fig. 4).

En estas fechas, la producción litográfica de temas coreográficos en España resulta prácticamente inexistente. Fiel reflejo de esta carencia fue la representación de Marie bailando el Jaleo sobre grabado, a partir de los dibujos que hizo Francisco Lameyer y que se publicaron entre 1845 y 1847 . La identificación de la bailarina dentro de la imagen litográfica, así como su plasmación sobre otro tipo de objetos, concretamente de algunas grandes figuras, como Marie GuyStéphan en España, precisa a su vez de otra consideración más allá de sus cualidades artísticas. Las bailarinas que alcanzaron un éxito rotundo, aclamadas por la prensa diaria y las revistas ilustradas, contratadas en los grandes teatros europeos, lograron esta posición debido a la simbiosis particular que estableció con ellas la danza como enlace con los intereses económicos y políticos del momento. En definitiva, se establece un intercambio de carácter propagandístico entre los capitales privados que se invertían en los espectáculos con las bailarinas, y la proyección profesional de sus artistas. Esta relación resultaba fundamental para el lanzamiento y la proyección de una bailarina, que una vez

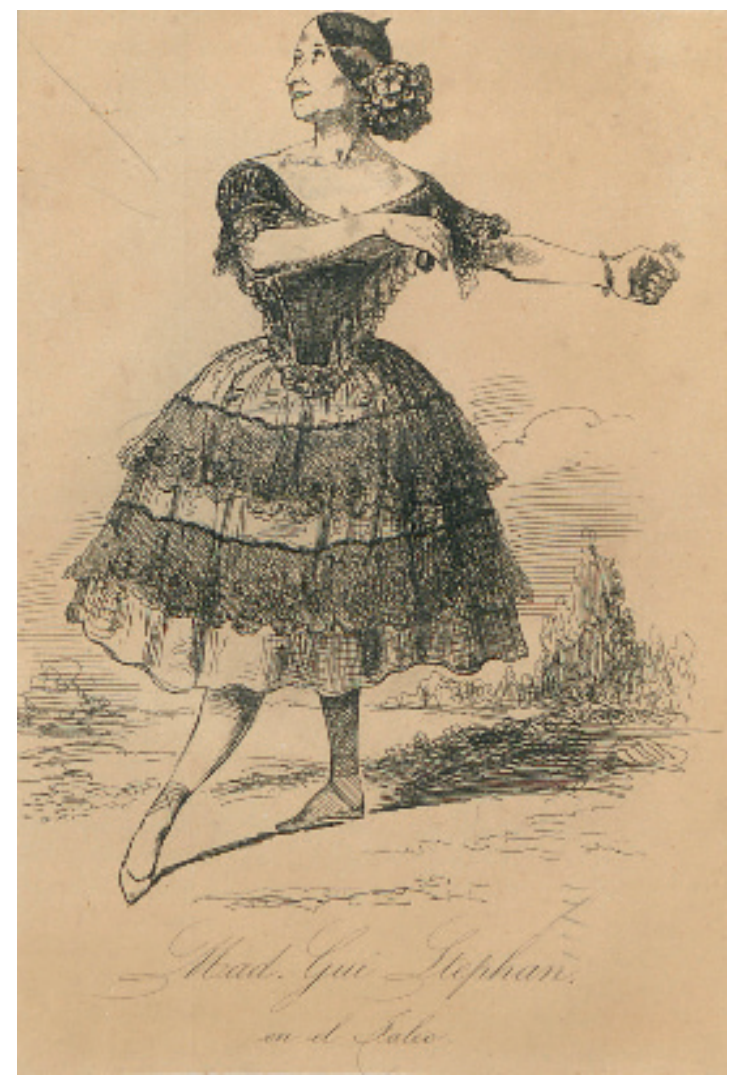

Fig. 4. "Mad. Gui Stéphan en el Jaleo". Grabado. Francisco Lamayer. Escenas Andaluzas. Estébanez Calderón. 1847. Biblioteca de la Universidad de Sevilla. obtenidos sus objetivos, se convertía en la principal expositora de los intereses crematísticos de su protector. Una publicidad mutua de la que participaron la prensa, los empresarios teatrales o la clap.

Por tanto, la imagen con la que sería retratada Marie, se identifica con el éxito que obtuvo para una producción que costeó José de Salamanca dentro de un gran espectáculo que creó para su empresa del Teatro del Circo. Por esto, cualquier aspecto de su imagen constituyó una iconografía, que se vino a identificar con el paso del Jaleo de Jerez, conformada por el atuendo y los complementos que le confeccionaron los modistos del teatro. Y en esto coinciden las imágenes que diseñó Lameyer para Estébanez y la imagen del daguerrotipo del IPCE, junto con otras producciones posteriores. Todas comparten exactamente un mismo vestido que se identifica a lo largo del tiempo con Marie y con su interpretación del Jaleo de Jerez. No sólo en las publicaciones que se realizaron entre 1845-1847, sino también en publicaciones realizadas varios años después, concretamente en 1850, en La linterna mágica ${ }^{27}$.

Esta indumentaria tiene unas características muy particulares. Fue diseñada por los modistos Manuela Fariñas y Lorenzo París para el paso del Jaleo de Jerez del tercer acto del ballet El

\footnotetext{
${ }^{26}$ Estébanez, Madrid, 1847.

27 La Linterna mágica: 1850: 5.
} 


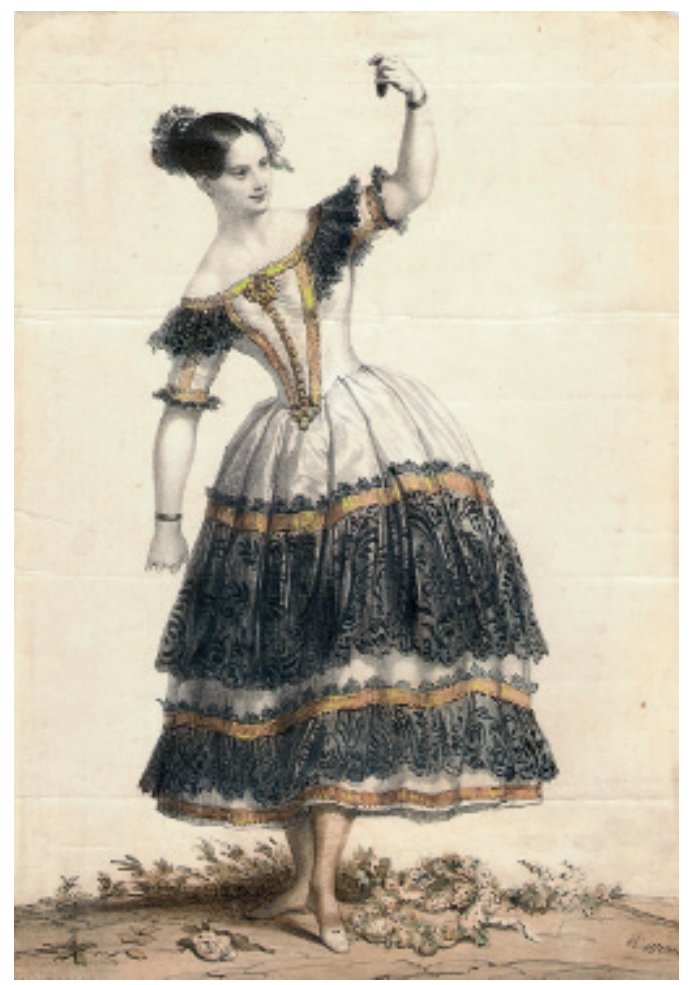

Fig. 5. Fanny Ellsler. La cachucha. A. Deveria. Goupil \&Vibert.

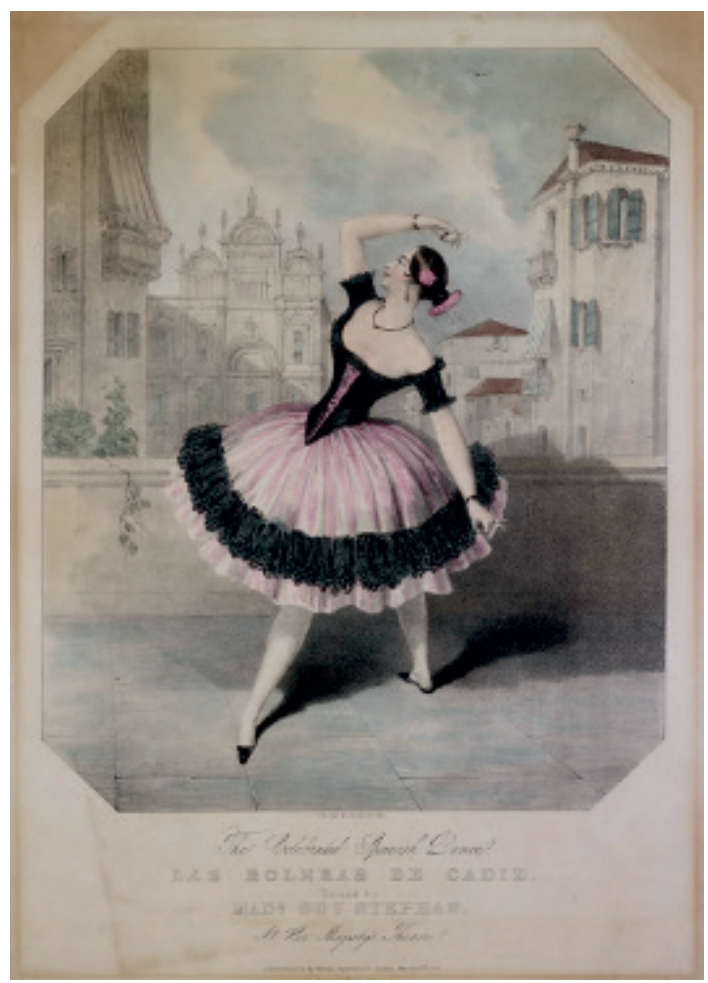

Fig. 6. Marie Guy-Stéphan. Boleras de Cádiz. 1844. Litografía de C.G. Lynch, a partir de una pintura de J. H. Lynch. Victoria \& Albert Museum.

diablo enamorado ${ }^{28}$. Desafortunadamente carecemos de descripciones adecuadas que permitan con rasgos precisos establecer una identificación ${ }^{29}$. No es algo que afecte exclusivamente al diseño de este figurín, sino a todos los que se exhibieron en cualquier escena nacional para espectáculos coreográficos en este tiempo. La ausencia de referencias precisas sobre los diseños de figurines de danza, es una carencia que acompaña a la inserción del ballet clásico y al desarrollo del baile español en este país, y se debe precisamente a la inexistencia de críticos especializados en espectáculos coreográficos. El traje que diseñaron Fariñas y París para el Circo, no se puede comprender sin dos diseños anteriores que fueron tomados como modelos, cuyas imágenes fueron difundidas ampliamente por la litografía. Se trata de la litografía de Fanny Elssler en el paso de la cachucha del Diable botieux de Achille Deveria, impresa por Cattier y publicada por Goupil and Vibert en París 1836; así como otra de la misma Marie Guy-Stephan en las Boleras de Cádiz de C. G. Lynch, publicada en Londres por William Spooner el 12 de marzo de 1844, a partir de una pintura de J. H. Lynch (figs. 5 y 6 ).

${ }^{28}$ Este paso lo compuso para ella Victorino Vera, segundo bailarín de la compañía y primero de la sección de bailes nacionales, con música de Juan Daniel Skoczdopole. El Clamor público, Madrid, 4-II-1845: 4.

29 Estos son algunos ejemplos de las alusiones que se publicaron en la prensa diaria: “(...) Los trajes son de lujo lujo, y de mucho gusto", La Posdata, Madrid, 29-I-1845: 3; “(...) trajes costosísimos hechos con el mayor gusto y elegancia”, El Clamor público, Madrid, 30-I-1845: 4; “(...) Efectivamente las decoraciones son magníficas lo mismo que los trajes”, El Heraldo, Madrid, 30-I-1845: 3; “(...) Vestida con toda la propiedad de una jerezana garbosa y terne”, El Laberinto, Madrid, 1-II-1845: 15. 
En ambas aparecen los bailes españoles con una diferencia de nueve años, identificados con una serie de elementos muy concretos, que desde la reproducción de la cachucha de Fanny en la estampa de Deveria se codificaron con una iconografía particular ${ }^{30}$. Por otra parte, ambos forman parte del diseño de un traje de baile identificado como español y creado por modistos de dos grandes teatros europeos, concretamente en el caso del traje de Fanny por Pierre Lormier y Henri Orschswiller en junio de 1836, y en el caso de Marie por el taller del Teatro Real de Londres. Esto resulta fundamental para comprender el vestido que luce la bailarina en el daguerrotipo del IPCE, pues es exactamente una pieza diseñada en su patrón y complementos partiendo de las dos creaciones anteriores, pues combina elementos de las dos producciones.

Resulta importante señalar que en estos años, este modelo de indumentaria de baile español producido en los grandes teatros internacionales, no era el habitual entre las bailarinas españolas de la escuela bolera, ni tan siquiera en las imágenes que sobre ellas se editaron en este tiempo. Estos diseños se realizaron siempre en grandes ballets producidos para teatros destinados a un público adinerado y aristocrático. Por estos motivos se trata de diseños que se asocian con escenas destinadas a espectadores de un alto nivel adquisitivo, que estimulaban la imagen que sobre España se estaba configurando en estos años. En definitiva, el diseño del traje de Marie fue creado en París, repetido y remodelado en Londres, y copiado en Madrid para el teatro socialmente más importante de la ciudad en 1845, gestionado por José de Salamanca como una parte más de sus negocios. Marie se incluye dentro del elenco de bailarinas convertida en un escaparate en el que se exhibían intereses dispersos y elevados, ajenos totalmente a su espectáculo. Su imagen pública está estrechamente unida al devenir político y económico del marqués de Salamanca en Madrid. Por estos motivos consideramos que no existe nada gratuito ni indeterminado en la plasmación de la imagen que aparece en el IPCE. El traje se convierte en un elemento identificador de la bailarina, del baile y de la sociedad que la aplaude, y son prendas diseñadas por modistos de teatro para grandes espectáculos; como también la imagen se convierte en un símbolo del estatus artístico alcanzado.

El traje de Marie que aparece en el daguerrotipo comparte con el de Fanny Elssler en su cachucha de 1836, y con el que lució ella misma en las Boleras de Cádiz en Londres en 1843, la saya o basquiña española corta, emplomada por los bajos y guarnecida con volantes de encaje negro; el corpiño de varillas en $\mathrm{v}$ unida a la falda con un acusado aguijón; las mangas cortas y ajustadas con un volante de encaje negro; escote amplio; varillas y estructura del armazón del corpiño rematado con galones; galón dorado en el cuello rematado con un volante de encaje negro. El pelo aparece recogido en un moño, adornado con una peina y flores en el lado de la cabeza. Las imágenes finalmente cuentan con pulseras ajustadas en las muñecas y castañuelas con sus cintas anudadas a los dedos.

Si bien estos son los elementos comunes, tienen ligeras diferencias, que oscilan entre un volante o dos, o en las zapatillas que llevan cintas o aparecen sin ellas principalmente. También destaca el color, que en el caso de los diseños de la saya de París y Londres es rosa, así como el tejido es satén, pero que desafortunadamente no podemos determinar en el caso del diseño del teatro del Circo, pues la imagen del daguerrotipo es una imagen coloreada sin más referentes. Sin embargo, podemos deducir que tanto el corpiño como la propia falda serían de este mismo tejido, tanto por el efecto de la luz sobre su textura, la caída de la prenda, como por la transparencia que ofrecen los encajes de los volantes. Finalmente aparece otra particularidad que resulta fundamental para identificar el traje del Jaleo de Jerez, ya que el corpiño está enriquecido con un volante de encaje que parte del extremo inferior de la misma prenda montado en $\mathrm{v}$ a lo largo del mismo hasta las mangas, lo que favorecería la imagen del juego de brazos durante el baile. Este pequeño detalle, que diferencia el traje de Marie en el Jaleo con respecto a los demás, aparece tanto en los grabados publicados en relación con la obra de Estébanez Calderón, como en el daguerrotipo del IPCE.

\footnotetext{
30 Sobre el traje de Fanny Elssler, Plaza: 2009: 156-172.
} 
La importancia que alcanzó esta indumentaria del Jaleo de Jerez que lució Marie como modelo entre las élites económicas y políticas de su tiempo, lo refleja el disfraz que lució la reina Isabel II en el baile de trajes que celebró en el Palacio Real durante el invierno de 184731; a lo que se añadiría que sobre este mismo patrón, con muchos de sus elementos y ligeras variantes, las señoras aristocráticas, especialmente andaluzas, se ataviaron con él para la fiestas, ferias, bailes de sociedad y otros eventos lúdicos en estos momentos ${ }^{32}$. La prensa diaria y las revistas ilustradas contribuirían decididamente a la consagración de este baile apoyando sin fisuras la calidad del ballet El Diablo enamorado, y el talento de su bailarina. Dentro de esta dinámica se encuentra la publicación de "El Solitario", Serafín Estébanez Calderón, en el Siglo Pintoresco en noviembre de 1845, y posteriormente su inclusión en sus Escenas Andaluzas desde 1846 hasta 1847, coincidiendo con el tiempo en que Marie cosechaba éxitos y aplausos en el Circo con el Jaleo de Jerez, y su cuñado José de Salamanca negociaba con él.

\section{BIBLIOGRAFÍA}

Beaumont, Ciryl W. / Sitwell Sacheverell (1938): The romantic ballet in lithographs of the time. London, Faber \&Faber. Borrego, Andrés (1855): Estudios políticos de la organización de los partidos en España. Madrid, Anselmo Santa Coloma.

Burdiel, Isabel (2010): Isabel II. Una biografía. (1830-1904), Madrid, Taurus.

Estébanez Calderón, Serafín (1847): "Escenas andaluzas, bizarrías de la tierra, alardes de toros, rasgos populares, cuadros de costumbres y artículos varios, que de tal y cual materia, ahora y entonces, aquí y acullá y por diverso son y compás, aunque siempre por lo español y castizo ha dado a la estampa", "El Solitario", ed. Adornada con 125 dibujos por DF Lameyer, Madrid, Baltasar González.

Gebelt, Tamara Lee (1995): The Evolution of the Romantic Ballet: The Libretti and Enchanter Characters of Selected Romantic Ballets From the 1830s Through the 1890s, Louisiana State University.

González Troyano, A (ed) (1985): Escenas Andaluzas, Madrid, Cátedra.

Hormigón, Laura (2010): Marius Petipa en España. Memorias y otros materiales. 1844-1847, Madrid, Danzarte ballet.

Hormigón, Laura (2017): El ballet romántico en el teatro del Circo de Madrid (1842-1850), Madrid, ADE.

Jowers, Sidney Jackson (2013): Theatrical costume, masks, make-up and wigs: a bibliography and iconography. Routledge.

Lavaur, Luis (1999): Teoría romantica del cante flamenco. Raices flamencas en la coreografía romántica europea, Sevilla, Signatura.

Llorca Vilaplana, Carmen (1984): Isabel II y su tiempo. Madrid, Istmo

Parmenia, Migel (1981): Great ballet prints of the romantic era. New York, Dover publications inc.

Plaza Orellana, Rocío (1999): El flamenco y los románticos. Un viaje entre el mito y la realidad. Sevilla, Bienal de Flamenco.

Plaza Orellana, Rocío (2005): Bailes de Andalucía en Londres y París (1830-1850). Puerto de Santa María, Arambel editores.

Plaza Orellana, Rocío (2009): Historia de la moda en España. El vestido femenino entre 1750 y 1850. Córdoba. Almuzara.

Plaza Orellana, Rocío (2013): Los bailes españoles en Europa. El espectáculo de los bailes de España en el siglo XIX. Almuzara, Córdoba.

Rodríguez Gutiérrez, Borja / Gutiérrez Sebastián, Raquel (2011): Literatura ilustrada decimonónica. 57 perspectivas. Santander, Servicio de publicaciones de la Universidad de Cantabria.

Tamvaco, Jean-Louis (2000): Les Cancans de l'Opéra. París, CNRS éditions.

Fecha de recepción: 17-X-2017

Fecha de aceptación: 15-I-2018

31 El Heraldo, Madrid. 19-I-1847: 4.

32 Plaza, 2009: 156-172.

Archivo Español de Arte, vol. XCI, n. ${ }^{\circ}$ 364, pp. 418-426, octubre-diciembre 2018

ISSN: 0004-0428, eISSN: 1988-8511, https://doi.org/10.3989/aearte.2018.26 